\title{
Cation binding by some pyranopyridothiazole derivatives
}

\author{
Olfa Naouali a, Hussain Soleiman b,c and Lassaad Baklouti a,b,* \\ a Laboratory of Applied Chemistry and Natural Substances Resources and Environment, Faculty of Sciences at Bizerte, Carthage University, Zarzouna-Bizerta, 7021, \\ Tunisia \\ b Chemistry Department, Sciences and Arts College, Al-Qassim University, Al-Rass, 53200, Kingdom Saudi Arabia \\ c Chemistry Department, Aswan Faculty of Sciences, Aswan University, Aswan 3567, Egypt \\ *Corresponding author at: Chemistry Department, Sciences and Arts College, Al-Qassim University, Al-Rass, 53200, Kingdom Saudi Arabia. \\ Tel.: +966.05.32056252. Fax: +966.016.3512515. E-mail address: bakloutilassaad@yahoo.fr (L. Baklouti).
}

\section{ARTICLE INFORMATION}

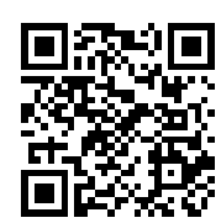

DOI: 10.5155 /eurjchem.5.2.339-342.1003

Received: 15 December 2013

Received in revised form: 23 February 2014

Accepted: 25 February 2014

Online: 30 June 2014

\section{KEYWORDS}

\section{Thiazole}

Extraction

Stoichiometry

Complexation

Stability constants

Inclusion properties

\section{Introduction}

The pyranopyridothiazole derivatives are biologically interesting molecules which have established utility in the pharmaceutical compounds. These ring systems have a wide application range in the biological activities and the pharmacological actions [1-5], such as antibacterial [6,7] and inhibitory activities [8-10]. Otherwise, the pyranopyrido thiazole derivatives found a wide uses in the industry compounds and the chemistry of dyes and pigments such as laser technologies $[11,12]$, colour and non-colour photographic processes [13], optical disk as recording media [14] and inks [15]. Recently, a different heterocyclic cyanine dyes have been reported as high sensitivity and low fogging information recording media of high reflectivity and carrier-to-noise ratio, laser disc media, lasersensitive optical recording material. Besides their use as colorants [16], they have considerable potential for application in energy conversion [17]. Moreover, the structure activity studies revealed that the synthesized compounds are also important in many other fields. Referring to our previous work [18], attempts have been made in order to synthesize a new fused and isolated heterocyclic compounds, as well as some compounds of cyanine dyes like apocyanine and monomethine cyanine dyes [19].

\section{Experimental}

\subsection{Instruments and materials}

The UV spectra have been recorded on a Perkin Elmer Lambda 11 spectrophotometer. Methanol (Riedel-deHaën for HPLC), acetonitrile (SDS for HPLC, $0.03 \%$ water content) and dichloromethane (Fluka, purum) are commercial and used without further purification. The supporting electrolyte used in the determination of the stability constant is $\mathrm{NEt}_{4} \mathrm{Cl}$ and $\mathrm{NEt}_{4} \mathrm{ClO}_{4}$ (Acros Organics). The chosen metal salts have been chlorides or perchlorates (Fluka, purum). The picrate salts employed in the extraction have been prepared as described in the literature $[20,21]$.

\subsection{Synthesis of thiazole derivatives ( $L 1, L 2, L 3$ and $L 4)$}

The synthesis of thiazole derivatives L1, L2, L3 and $\mathbf{L} \mathbf{4}$ have been achieved via interaction of 4,5-dihydro-2-ehylacetate-4oxothiazole $\mathbf{L 1}$ with benzilidenemalononitrile $\mathbf{L 2}$, amido acrylonitrile $\mathbf{L} 3$ and amido cinnamonitrile $\mathbf{L 4}$ according to $\mathrm{Al}-$ Ayed et al. [19] (Figure 1). 


\begin{tabular}{|c|c|c|c|c|c|c|c|c|c|c|}
\hline Ligands & M:L & Co(II) & $\mathrm{Ni}(\mathrm{II})$ & $\mathrm{Cu}(\mathrm{II})$ & Zn(II) & $\mathrm{Cr}$ (II) & Mn(II) & $\mathrm{Fe}(\mathrm{III})$ & $\mathrm{Pb}(\mathrm{II})$ & $\operatorname{Sn}($ II) \\
\hline $\mathrm{L} 1$ & $1: 1$ & $-*$ & 3.42 & 3.03 & 3.09 & 4.10 & 4.40 & 4.07 & 4.01 & 3.04 \\
\hline L2 & $1: 1$ & 4.10 & 3.30 & 3.19 & - & - & - & 3.20 & - & - \\
\hline L3 & $1: 1$ & 2.90 & 3.12 & 3.03 & 3.09 & - & - & 3.16 & - & - \\
\hline L4 & $1: 1$ & 2.10 & 3.85 & 3.19 & 3.65 & - & 3.01 & 3.50 & - & 4.05 \\
\hline
\end{tabular}

$*_{-}$-: Absorbance changes too small to enable satisfactory fitting.

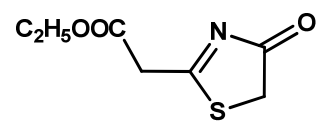

L1: Cyanopyranopyridothiazole<smiles>NC(=O)C1=C(c2ccccc2)C(=O)C(N=c2c3c(N)c(-c4ccccc4)c(N)c(C(N)=O)c23)O1</smiles>

L3: Iminothiazole<smiles>N#CC1=C(c2ccccc2)OC2N=C(C3C(=N)C(C#N)=C(c4ccccc4)C3=O)SC2=C1N</smiles>

L2: Aminothiazole

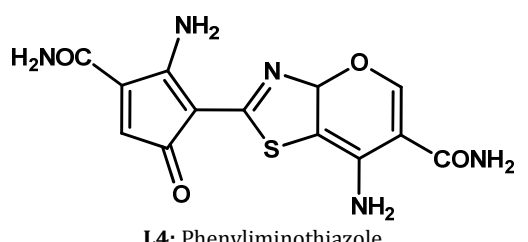

Figure 1. Chemical structure of ligand.

\subsection{Stability constant measurements}

The stability constants $\beta_{\mathrm{xy}}$ are the concentration ratios $\left[\mathrm{M}_{\mathrm{x}} \mathrm{Ly}^{\mathrm{xn}+}\right] /\left[\mathrm{M}^{\mathrm{n}+}\right]^{\mathrm{x}}[\mathrm{L}]^{\mathrm{y}}$ following the general equilibrium:

$\mathrm{yL}+\mathrm{xM}^{\mathrm{n}+} \leftrightharpoons \mathrm{M}_{\mathrm{x}} \mathrm{Ly}^{\mathrm{xn}+}$

where $\mathrm{M}^{\mathrm{n}+}$ : metal ion, L: ligand have been determined in acetonitrile and methanol by UV-absorption spectrophotometry at $25^{\circ} \mathrm{C}$.

The ionic strength has been maintained at $0.01 \mathrm{~mol} / \mathrm{L}$ using $\mathrm{Et}_{4} \mathrm{NClO}_{4}$. The spectra of ligand solutions of concentrations ranging between $1 \times 10^{-4}$ and $2 \times 10^{-4} \mathrm{~mol} / \mathrm{L}$ and increasing the metal ion concentration has been recorded between 220 and $400 \mathrm{~nm}$. Generally the metal to ligand ratio $\mathrm{R}$ at the end of the titration did not exceed 20 and the equilibriums were quasiinstantaneous for all the systems. Adding the metal salts to the ligand has induced large spectra changes which were enough to allow the analysis of the resulting data using the program "Letagrop" [22]. The best values of the formation constants $\beta_{\mathrm{xy}}$ of the various complex species and their molar absorptivity coefficients for various wavelengths are deduced from the best fit between the experimental and the calculated UV spectra.

The best fit is reflected by the lowest value of $U$ (the sum of $\mathrm{U}$ values for all given lambda) corresponding to the square sum of the difference between the experimental and the calculated absorbances $\left(U=\sum\left(A_{\text {cal }}-A_{\text {exp }}\right)^{2}\right)$. The $\beta_{x y}$ values correspond to the arithmetic means of at least three independent experiments.

\subsection{Conductimetric studies}

While the complexation by a neutral ligand is not expected to dramatically alter the molar conductivity of a cationic species, the differences can usually be detected and so the conductance measurement of a ligand solution in to which a metal ion is added can be a useful rapid means of establishing the stoichiometry of a complex ion species. Thus, this procedure was followed to obtain preliminary estimations of the metal ligand ratio in the complexes formed by the heterocyclic amine in methanol solution $[23,24]$.

\subsection{Extraction studies}

The extraction experiments of alkali metal picrates from water into dichloromethane is performed according to a literature procedure [23]. Equal volumes $(5 \mathrm{~mL})$ of neutral aqueous solutions of metal picrate $\left(2.5 \times 10^{-4} \mathrm{~mol} / \mathrm{L}\right)$ and $\mathrm{CH}_{2} \mathrm{Cl}_{2}$ solution $(5 \mathrm{~mL})$ of ligand $\left(2.5 \times 10^{-4} \mathrm{~mol} / \mathrm{L}\right)$ have been mixed under magnetic agitation for 24 hours and then left standing for 1 hour in order to obtain a complete separation of the two phases.

The concentration of metal picrate remaining in the aqueous phase has been determined from the absorbance $A$ at $355 \mathrm{~nm}$. The percentage extraction $(\% \mathrm{E})$ was derived from the following expression in which Aorepresents the absorbance of the aqueous solution of a blank experiment without ligand:

$\% \mathrm{E}=100\left(\mathrm{~A}_{0}-\mathrm{A}\right) / \mathrm{A}_{0}$

\section{Results and discussion}

\subsection{Complexation of metal cations in methanol}

The complexation study of alkali and alkaline earth cations with L1-L4 shows no affinity toward these cations. However, the mononuclear complexes $(1: 1)$ could be shown with the transition metal cations. The logarithms of the stability constants $\log \beta_{\mathrm{xy}}$ and the stoichiometries for the different complexes formed by the ligand with some transition metals in methanol are given in Table 1.

The transitions metal cations studied in this work show affinities of complexation with the $\mathbf{L 1}, \mathbf{L 2}, \mathbf{L 3}$ and $\mathbf{L 4}$ despite of its total absence with the monovalent and divalent cations (alkaline and alkaline earth cations). This is likely due to the difference in hardness of the considered cations.

The selectivity profile of the ligand $\mathbf{L 1}$ in the transition metal series shows an affinity in case of iron and chromium complexing in methanol, while this becomes an affinity for cobalt in methanol with the ligand L2. In the other hand, the stability of the complexes formed with $\mathbf{L} \mathbf{3}$ are at the same order of magnitude, which shows that this complexation is not affected by the effect of the size in the case of the studied transition metal cations (Figure 2). 


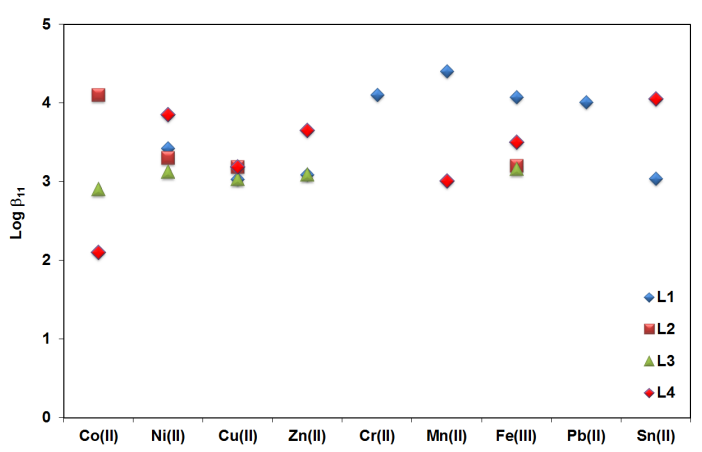

Figure 2. Stability constants $\log \beta_{11}$ (determined in methanol) for some transition metal and heavy metal cations with L1-L4.

Similarly ligand $\mathbf{L} \mathbf{4}$ for stability of the complexes formed with $\mathrm{Ni}(\mathrm{II})$ shows an improved stability in methanol and lower complexation with $\mathrm{Cu}(\mathrm{II})$. It is worth to note that the passage from L2 to L4 decreases dramatically the Co(II) complexation (100 times). Moreover, the variation of the selectivity profiles suggests that a non-dominant cation size in the complexation phenomenon would be also an interesting factor. The basic pattern of the $\mathbf{L 1}$ ligand has an affinity for complexing transition metal cations such as chromium and lead and shows the formation of mononuclear complex. The transition to cyanopyranopyridothiazole L2 shows the formation of 1:1 complexes with $\mathrm{Ni}(\mathrm{II}), \mathrm{Cu}(\mathrm{II}), \mathrm{Co}(\mathrm{II})$, and $\mathrm{Fe}(\mathrm{III})$, while it has no affinity for Zn(II), Mn(II), Sn(II), Cr(II) and Pb(II) (Figures 3-5).

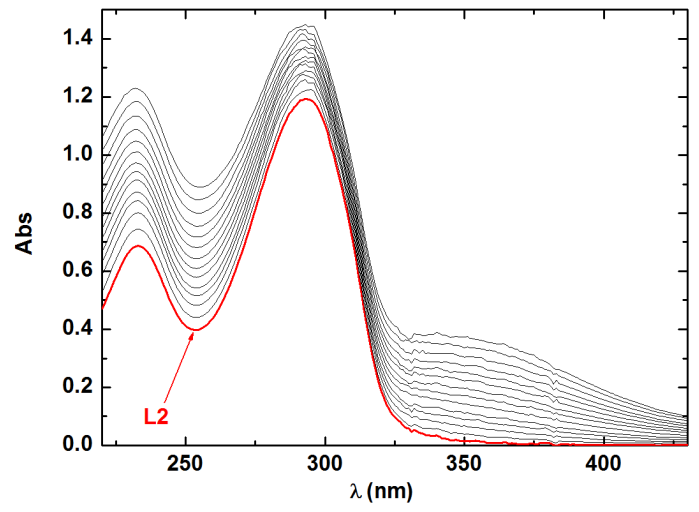

Figure 3. UV absorption spectra on complexation of Fe(III) with L2 in methanol $\left(0 \leq \mathrm{R}_{\mathrm{M} / \mathrm{L}} \leq 2\right)$ at $25^{\circ} \mathrm{C}$.

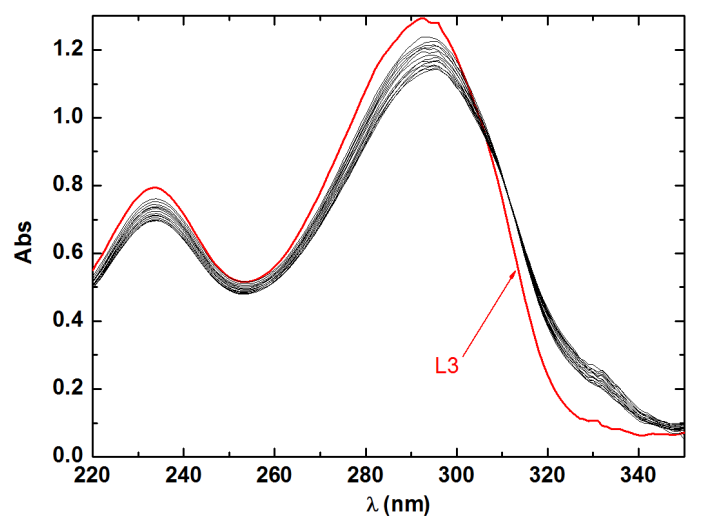

Figure 4. UV absorption spectra on complexation of Zn(II) with $\mathbf{L 3}$ in methanol $\left(0 \leq \mathrm{R}_{\mathrm{M} / \mathrm{L}} \leq 3\right)$ at $25^{\circ} \mathrm{C}$.

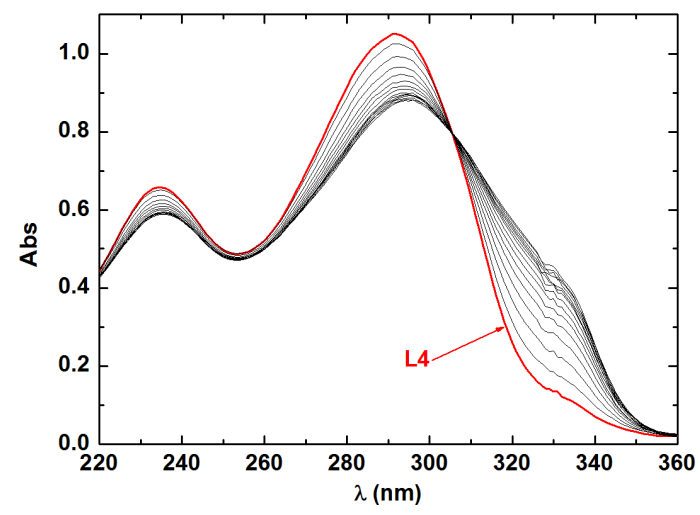

Figure 5. UV absorption spectra on complexation of Ni(II) with L4 in methanol $\left(0 \leq \mathrm{R}_{\mathrm{M} / \mathrm{L}} \leq 5\right)$ at $25^{\circ} \mathrm{C}$.

By going against the imine function and oxidation of the ligand L3 nitrile function, is accompanied by a decreased affinity of complexing with metal cations include Sn(II) and $\mathrm{Mn}(\mathrm{II})$.

However, L4 shows affinity for the Sn(II) and theMn(II), this is probably due to the geometry of more flexible ligand in absence of the phenyl groups. It is noteworthy that the oxidation of the nitrile function of the ligand $\mathbf{L} 2$ to the amide function of ligand $\mathbf{L} 3$ increases the affinity of the $\mathrm{Zn}$ (II) cation complexing. On the other hand, the amide appears to decrease the ligandL3 affinity complexation with the $\mathrm{Cr}(\mathrm{II}), \mathrm{Pb}(\mathrm{II}), \mathrm{Sn}(\mathrm{II})$ and $\mathrm{Mn}(\mathrm{II})$ comparing to the ligand L1. Furthermore, the stoichiometries of 1:1 complexes with L1-L4 were confirmed by the conductimetric studies (Figure 6).

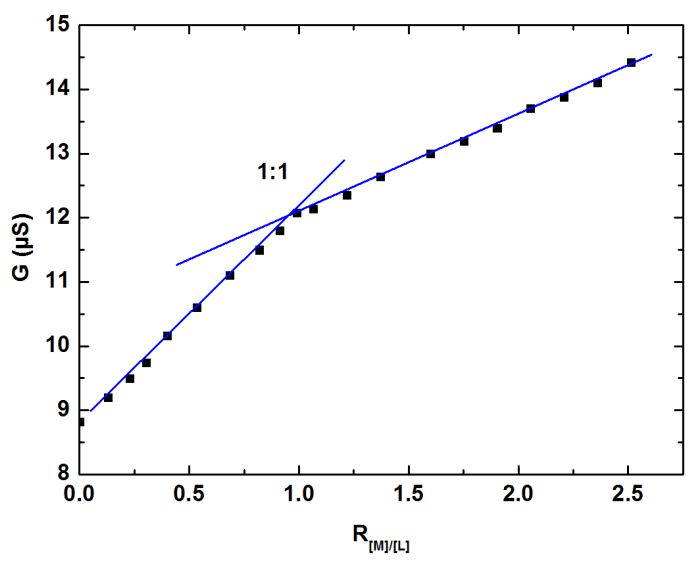

Figure 6. Conductometric titration in the case of $\mathbf{L 4}$ with $\mathrm{Cu}(\mathrm{II})$.

Indeed, the stoichiometries determined by the conductometric study of L1-L4 with the cations Ni(II) and $\mathrm{Cu}(\mathrm{II})$ have clearly confirmed those derived from the study by the UV spectrophotometry.

\subsection{Extraction of metal picrates}

A preliminary evaluation of the binding efficiency of pyranopyridothiazole derivatives has been carried out through by solvent extraction of metal picrates into dichloromethane at $20{ }^{\circ} \mathrm{C}$ under neutral conditions. The extraction percentages (\%E) of some transition metal picrates by $\mathbf{L 1}, \mathbf{L 2}, \mathbf{L 3}$ and $\mathbf{L 4}$ from water into dichloromethane are given in Table 2.

In the series of the metal cations studied, the $\% \mathrm{E}$ obtained with $\mathbf{L 1}$ is lower ( $<10 \%)$, but for L2-L4 the \%E varies between 18 and $53 \%$. 
Table 2. Extraction percentages $(\% \mathrm{E})$ of some transition metal picrates by $\mathbf{L 1}, \mathbf{L 2}, \mathbf{L} \mathbf{3}$ and $\mathbf{L 4}$ from water into dichloromethane, at $25{ }^{\circ} \mathrm{C}\left(\mathrm{CL}=\mathrm{CM}=2.5 \times 10^{-4}\right.$ $\mathrm{mol} / \mathrm{L})$.

\begin{tabular}{llllllll}
\hline Ligands & Co(II) & Ni(II) & Cu(II) & Zn(II) & Mn(II) & Fe(III) & Pb(II) \\
\hline L1 & 9 & 6 & 5 & $\leq 1$ & $\leq 1$ & 4 \\
L2 & 23 & 25 & 35 & 32 & 22 & 18 & 37 \\
L3 & 36 & 28 & 39 & 27 & 24 & 46 \\
L4 & 47 & 34 & & 27 & 30 & 35 \\
\hline
\end{tabular}

However, $\mathbf{L 4}$ is a better extractant than $\mathbf{L} 2$ and $\mathbf{L 3}$ in the series of ligands studied. Looking at the series of cations considered, Fe(III) is a better extract then M(II) cations studied. So, the pyranopyridothiazole derivatives studied do not hexibe meaning selectivity (Figure 7).

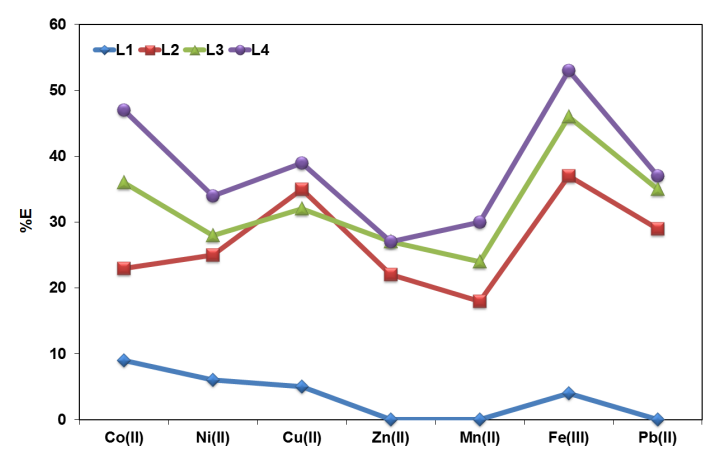

Figure 7. Trends of the extraction percentages $(\% \mathrm{E})$ for some transition metal and heavy metal picrates from water into dichloromethane with L1-L4.

\section{Conclusion}

The formation of mononuclear species to a ligand L1, L2, L3 and L4 complex with transition metals and heavy metals has been established in this work. The conductimetric titration confirmed mainly the stoichiometries of complexes formed in solution with L1, L2, L3 and L4 determined by the UV spectrophotometric study. However, the extraction study shows a lower extraction affinity for the metal picrates with $\mathbf{L 1}$, while L2-L4 are better extracted and specially Fe(III) with $\mathbf{L 4}$.

\section{Acknowledgement}

Special thanks go to Prof. Dr. MalikaTrabelsi Ayadi (LACReSNE-Bizerte) for her invaluable support.

\section{References}

[1]. Gangjee, A.; Aldair, O.; Queene, S. F. J. Med. Chem. 1999, 42, 24472455.

[2]. Grivsky, E. M.; Lee, S.; Sigel, C. W.; Duch, D. S.; Nichol, C. A. J. Med. Chem. 1980, 23, 327-329.

[3]. Matulenko, M. A.; Lee C. H.; Jiango, M.; Free, R. R.; Cowart, M. D.; Bayburt, E. K.; Didomenico, S. J.; Gfesser, G. A.; Gomtsyan, A.; Zheng, G. Z.; Mckie, J. A.; Stewart, A. O.; Yu, H.; Kahlhass, K. L.; Alexander, K. M.; McGaraughty, S.; Wismer, C. T.; Mikusa, J.; Marsh, K. C.; Snyder, R. D.; Diehl, M. S.; Kowaluk, E. A.; Jarvisa, M. F.; Bhagwata, S. S. Bioorg. Med. Chem. 2005, 13, 3705-3720.

[4]. Zheng, G. Z.; Lee, C. H.; Patt, J. K.; Perner, R. J.; Jlang, M. O.; Gonitsyan, A. Matulenko, M. A.; Mao, Y.; Koenig, J. R.; Kim, Muchmore, S.; Yu, H.; Kohlhaas, K.; Alexander, K. M.; McGaraughty, S.; Chu, K. L.; Wismer, C. T.; Mikusu, J.; Jarvis, M. F.; Marsh, K.; Kowaiuk, E. A.; Bhagwata, S. S.; Stewarta, A. O. Bioorg. Med. Chem. Lett. 2001, 11, 2071-2074.

[5]. Gfesser, G. A.; Bayburt, E. K.; Cowart, M.; DiDomenico, S.; Gomtsyan, A.; Lee, C. -H.; Stewart, A. O.; Jarvis, M. F.; Kowaluk, E. A.; Bhagwat, S. S. Eur. J. Med. Chem. 2003, 38, 245-252.

[6]. Soleiman, H. A.; Khalafallah, A. K.; Abdelzaher, H. M. J. Chin. Chem. Soc. 2000, 47, 1267-1272.

[7]. Soleiman, H. A.;Koraim, A. I. M.;Mahmoud, N. Y. J. Chin. Chem. Soc. 2004, 51, 530-533.

[8]. Gfesser, G .A.; Bayburt, E.K.; Cowart, M.; DiDomenico, S.; Gomtsyan, A.; Lee, C. H.; Stewart, A. O.; Jarvis, M. F.; Kowaluk, E. A.; Bhagwat, S. S. Eur. J. Med. Chem. 2003, 38, 345-353.
[9]. Ravi, K. S.; Venkat, R. G; Hara, K. K.; Shanthan, R. P.; Narsaiah, B.; Surya, N. M. U. Eur. J. Med. Chem. 2006, 41, 1011-1016.

[10]. Soleiman, H. A. Open Catal. J. 2010, 3, 107-115.

[11]. Dgdyusha, G. G.; Zubarovskii, V. M.; Moreiko, V. M.; Parhomskaya, O. V.; Sych, E. D.; Tikhonov, E. A.; Khodot, G. P. 1978 USSP Patent 568318 Appln: 215763; Chemical Abstract, 1975, 90, 46509j.

[12]. Inagaki, Y: Adachi, K. Yabe, M. 1988, GerOffen. DE 3819688 (C1G 11B7124) Appl. 87143 46809; Chemical Abstract, 1988, 111, 68030a.

[13]. Ikeat, T.; Takei, H.; Yamashita, H. 1985, Eur Pat. Appl. Ep. 144091 (1C031128); Chemical Abstract, 1985, 104, 12987.

[14]. Sun, S.; Chen, P.; Zheng, D. (Proc. SPIE-Int. Soc. Opt. Eng. 1998, 3562 (Optical Storage Technology), 11, 16 (Eng.), SPIE. Chemical Abstract, 1999, 130, 175194w.

[15]. Onodera, A.; Ninomia, H.; Ghya, H.; Ishibashi, D.; Komamura, T., Katoh, K.; Tanaka, T.; Morimoto, R. (Konica Corporation, Japan). Eur. Pat Appl. Ep 7C9, 53j (C1CO9B 55100), 23 Apr. 1997. Jp Appl. 96172, 257 27 Mar 1996, 55 pp. (Eng). Chemical Abstract, 1997, 126, 344433t.

[16]. Fabian, J.; Hatmann, H. Light Absorption of Organic Colorants, Springer, 1980, pp. 162-197.

[17]. Rochlitz, J. Chimia 1980, 34, 131-144.

[18]. Alayed, A. S. Can. J. Chem. Eng. 2011, 2, 87-105.

[19]. Alayed, A. S.; Soleiman, H. A. Int. J. Basic App. Sci. 2011, 11, 1-8.

[20]. Pedersen, C. J. Am. Chem. Soc. 1970, 92, 386-391.

[21]. Frensdorff, H. K. J. Am. Chem. Soc. 1971, 92, 4684-4686

[22]. Sillen, G.; Warnquist, B. Ark. Kemi. 1968, 31, 377-390.

[23]. Ben Othman, A.;Baklouti, L.; Abidi, R.; Vicens, J. Lett. Org. Chem. 2007, 4, 339-343.

[24]. Thabet, W.; Baklouti, L.; Zieba, R.; Parola, S. J. Inclusion Phenom. 2012 73, 135-139. 